\title{
El cambio de la geopolítica internacional frente al narcotráfico tras el Acuerdo Final en Colombia ${ }^{1}$
}

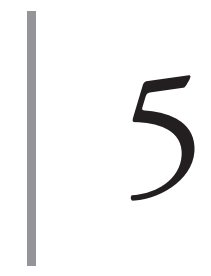

https://doi.org/10.21830/9789585284869.05

\author{
Manuel Bermúdez-Tapia ${ }^{2}$ \\ Universidad Privada San Juan Bautista \\ Paola Alexandra Sierra-Zamora ${ }^{3}$ \\ Escuela Superior de Guerra "General Rafael Reyes Prieto"
}

\section{Introducción}

El 24 de noviembre del 2016 se suscribe el Acuerdo Final para la Terminación del Conflicto y la Construcción de una Paz Estable y Duradera (en adelante, Acuerdo Final) entre el Gobierno nacional de Colombia y las Fuerzas Armadas Revolucionarias de Colombia - Ejército del Pueblo (FARCEP) en la ciudad de Bogotá, tras un proceso de negociación que empezó el 4 de septiembre del 2012, cuyas negociaciones tuvieron lugar en La Habana (Cuba) y Oslo (Noruega). Este conflicto entre el Gobierno nacional de Colombia y uno de los grupos beligerantes con el cual se enfrentó durante

1 Este capítulo hace parte de los resultados del proyecto de investigación "Estrategia nacional: por una Política de Seguridad y Defensa a la vanguardia de las amenazas contemporáneas" del Grupo de Investigación Masa Crítica, de la Escuela Superior de Guerra "General Rafael Reyes Prieto", registrado con el código COL0123247 de Minciencias.

2 Abogado (magna cum laude) de la Pontificia Universidad Católica del Perú. Magíster en Derecho y PhD en Derecho por la Pontificia Universidad Católica de Argentina. Profesor-investigador de la Universidad Privada San Juan Bautista y profesor de la Facultad de Derecho de la Universidad Nacional Mayor de San Marcos. Orcid: http://orcid.org/0000-0003-1576-9464 - Contacto: manuel.bermudez@upsjb. edu.pe

3 Abogada de la Universidad Católica de Colombia. Magíster en Derechos Humanos, Democracia y Justicia Internacional por la Universitat de València (España) y PhD (c) en Derechos Humanos, Democracia y Justicia Internacional de esta misma casa de estudios. Gestora de investigación del Departamento de Estrategia de la Escuela Superior de Guerra "General Rafael Reyes Prieto". Investigadora del Grupo de Investigación Persona, Instituciones y Exigencias de Justicia, de la Universidad Católica de Colombia, reconocido con código COL0120899, categoría A1 de Colciencias. Contacto: paola.sierra@esdegue.edu.co - Orcid: https://orcid.org/0000-0002-3146-7418 
más de cincuenta años fue uno de los principales problemas del país en su vida republicana, además de la situación de conflicto interno con otros grupos armados semejantes.

Sin embargo, la particularidad del conflicto contra las FARC-EP es el hecho de la variación de la propia naturaleza del grupo insurgente, que fue cambiando a lo largo del tiempo. Las FARC-EP se crearon sobre la base de una línea de pensamiento ideológico, pero en los últimos años se observaba una peligrosa alianza con sectores vinculados al narcotráfico, que alejaban a este grupo de sus propios orígenes. Una relación peligrosa que provocó una evaluación geopolítica sobre Colombia, en particular, porque los nexos entre los grupos sediciosos y el narcotráfico involucraban a otros países de la región, razón por la cual la "lucha frontal" resultaba estéril. Además, la situación resultaba de alta complejidad por la relación entre elementos como las zonas de conflicto del país y las condiciones de vinculación económica de estas con grupos de narcotraficantes.

Estos factores quedaron en evidencia en las evaluaciones generadas por el bombardeo de Angostura, al ejecutarse la Operación Fénix en territorio ecuatoriano (Torres, 2009). En dichas evaluaciones se acreditó que uno de los factores económicos que sostenía a las FARC-EP era el narcotráfico. Una referencia muy importante, que registra un factor precedente por medio del cual se descubrió que el Gobierno peruano, con Alberto Fujimori y Vladimiro Montesinos, había vendido armas a las FARC-EP (Marcy, 2010), empleando recursos financieros del erario nacional peruano (De La Pedraja, 2016).

De esta forma, el narcotráfico, al perder un aliado estratégico muy importante en este país — que le permitía ser el nexo entre los países productores de hoja de coca (Bolivia y Perú) y México (el país referente como exportador en el manejo de las líneas de acción del narcotráfico a nivel mundial)— se vio forzado a generar nuevas estrategias que determinarían otras condiciones, en las cuales la geopolítica se aplicaría en los países de la región latinoamericana.

En el ámbito político, Santana (2004) inclusive llega a identificar la vinculación política de sectores políticos que apoyan las acciones del narcotráfico en contra de los intereses de sus propios países y esto es una realidad bastante generalizada en la región latinoamericana. 


\section{El ocaso de la alianza entre grupos paramilitares y el narcotráfico}

El Acuerdo Final de Paz en Colombia no es la única referencia en América Latina que señala la relación de negociación entre un grupo guerrillero y el Gobierno de un país. En el Perú, bajo otro contexto político, económico y social, es posible identificar un antecedente particular respecto del caso colombiano, tomando en cuenta el conflicto armado interno que se generó entre 1980 y 1992 (fecha de la captura de Abimael Guzmán). En este ámbito, es posible determinar algunos elementos referenciales que permiten identificar semejanzas y particularidades entre las realidades de Perú y Colombia:

a. En Perú y Colombia, los grupos beligerantes empezaron una línea de acción contra el Gobierno nacional sobre la base de una ideología política vinculada al ámbito del comunismo (Villamarín, 2014), sobre la cual estructuraron un mecanismo de confrontación directa contra las Fuerzas Armadas del Perú y las Fuerzas Militares de Colombia.

b. Los grupos Sendero Luminoso (Contreras, 2014), Movimiento Revolucionario Túpac Amaru y FARC-PE basaron su estrategia de beligerancia sobre la base del dominio de un territorio usualmente ajeno a la intervención del Estado en el sentido amplio del término. Las condiciones económicas, sociales, culturales y de accesibilidad a dichos territorios fueron un patrón que permitió no solo la ubicación de un espacio de dominio excluyente frente al Estado, sino también donde podían emplear a la población, de forma directa e indirecta, mediante la intimidación o la captación de miembros, ante la limitación de posibilidades de oposición de la población.

c. En Perú y Colombia, el conflicto interno provocó la generación del concepto "problema-país" (Basombrío \& Rospigliosi, 2006) y la incidencia negativa se evidenció profundamente en el ámbito económico, social, cultural y político.

d. En Perú no se registró ningún acuerdo de paz o mecanismo equivalente, sino lucha directa contra el terrorismo, categoría terminoló- 
gica que identificó el período de confrontación interna y que se ha dividido en dos ámbitos:

i. La lucha contra Sendero Luminoso prácticamente ha desaparecido desde 1992, con la captura de Abimael Guzmán, cabecilla de dicho grupo terrorista. En la actualidad, subsisten grupos microscópicos de Sendero Luminoso en una zona de alta consideración geoestratégica para el narcotráfico: los Valles de los ríos del Apurímac y Ene, en las regiones de Ayacucho, Huancavelica y Apurímac, donde la geografía es el mejor aliado de estos grupos que han mutado su estrategia política, como servicio de seguridad contratado por los grupos de narcotraficantes que operan en la zona (Jaskoski, 2013).

ii. La lucha contra el Movimiento Revolucionario Túpac Amaru finalizó cuando un grupo generó la toma de la Embajada de Japón en Lima (1996), que provocó el asalto a dicho inmueble por las Fuerzas Armadas peruanas en 1997, con lo cual todos los terroristas fueron abatidos (Del Alcàzar, 2007). En ambas situaciones, la "finalización" de la lucha contra el terrorismo no identifica un período o hecho en particular y por ello es posible detallar registros de acciones muy esporádicas o referenciales en el país.

e. En el Perú, el terrorismo ha tenido dos elementos ideológicos muy particulares.

i. Sendero Luminoso tenía una influencia del marxismo, el leninismo y el pensamiento de Mao Zedong, sobre la cual se buscaba la toma del poder para generar un nuevo panorama político, sin que ello implicara necesariamente la mejora de la calidad de vida de los "insurgentes", quienes en su mayoría eran campesinos bajo la dirección de profesionales vinculados a profesiones liberales. De acuerdo con esta ideología, la premisa básica era el acceso al poder mediante el terror y por ello el apoyo popular fue muy débil, pero las zonas de influencia permitían la movilización de sus huestes frente al accionar de las Fuerzas Armadas. 
ii. El Movimiento Revolucionario Túpac Amaru, a diferencia de Sendero Luminoso, no tenía un ámbito ideológico tan notorio, salvo la línea de acción de su líder Víctor Polay Campos, de formación aprista en su juventud.

Un hecho que permite señalar la amistad con Alan García Pérez — debido a que ambos habían compartido vivienda y estudios en España en la juventud- fue la intervención de este, siendo presidente, en la inacción del Estado peruano ante la fuga de Polay y los principales líderes del MRTA en 1990, a días de la finalización del gobierno del APRA (Arce, 2007) Finalmente, en el período 1990-1997, el MRTA se asoció con el narcotráfico de manera directa debido a la influencia que ejercía en las zonas andino-amazónicas, donde la producción de la hoja de coca era sumamente fácil. Este hecho lo acabó de deslegitimar socialmente, sumado que nunca había tenido simpatía popular.

f. En el Perú, a pesar de haber finalizado (informalmente) el conflicto armado interno, las condiciones sociales, económicas, productivas y de conectividad nacional siguen siendo sumamente limitadas en las zonas en las que se había registrado el terrorismo.

g. En el Perú, el problema social y cultural que provocó el terrorismo generó un contexto de violencia social con actos de racismo y discriminación que han resurgido con niveles agudos en toda la sociedad nacional.

h. A diferencia de Colombia, en el Perú no se ha aceptado la participación política de los líderes del terrorismo, de los miembros de estos grupos o simpatizantes, a pesar de haberse registrado intentos de "asimilación" a la vida civil y política del país.

Organizaciones de apoyo a Sendero Luminoso, en forma exclusiva, no han logrado ni tener registro formal u oficial en el país ni menos tener acceso a estatus de grupo político.

i. Finalmente, la mayoría de los líderes terroristas registran una condena penal efectiva que va entre los 25 años y la cadena perpetua, 
pero aún hay muchos casos abiertos, y por ello es que las condenas penales se han registrado nuevamente contra dichos terroristas, por ser "nuevos casos".

Sin embargo, buena parte de líderes terroristas han sido liberados, tras el cumplimiento de la condena penal y, pese a los severos actos ejecutados, cuentan con el beneficio legal de ser considerados "rehabilitados socialmente".

El registro de estos elementos permite entonces identificar un contexto que no resulta ajeno a la evaluación de lo sucedido en Colombia.

\section{La realidad colombiana antes del Acuerdo de Paz}

La realidad colombiana en una etapa preacuerdo de paz permite analizar tres elementos importantes en el contexto del conflicto armado generado por las FARC-EP:

a. La beligerancia contra el Estado, como grupo armado y terrorista. Las acciones políticas y de acción armada ejecutadas por las FARC-EP demuestran que la confrontación militar era el principal elemento que le daba "legitimidad" a su poder ante el Gobierno nacional, en particular, por la ilegalidad de sus acciones frente a los derechos humanos y el derecho internacional humanitario.

b. Las acciones ejecutadas por las FARC-EP en el ámbito de la incidencia en la comunidad nacional. En este punto se pueden señalar cinco grandes grupos poblacionales que resultan vinculados directa o indirectamente:

i. El grupo de mayor incidencia y número está conformado por los integrantes de las FARC-EP.

ii. Los grupos de disidentes que no pudieron insertarse en la vida social colombiana, porque no podían ejecutar acciones civiles ordinarias ante el temor de ser ubicados por las FARC-EP. 
iii. Los campesinos, que son el grupo económicamente más condicionado por las acciones de las FARC-EP. Muchos de ellos se ven forzados a continuar con las acciones de cultivo de hoja de coca, porque no cuentan con otros mecanismos o fuentes de productividad económica en el ámbito agrícola.

iv. Los grupos de narcotraficantes que deberán buscar nuevos aliados, tanto en lo militar como en lo económico.

v. La población ajena a las cuatro ratios preliminares, que deberá procurar construir una nueva nación con base en un nuevo período republicano.

c. Las relaciones internacionales con Perú, Bolivia y México. Las alianzas que se habían mantenido con estos países se modificarán en virtud de las nuevas acciones que desarrollen los grupos vinculados al narcotráfico, y esta nueva realidad permite evaluar el aspecto desarrollado en el apartado siguiente (Tokatlian, 2000).

\section{El nuevo escenario mundial tras el Acuerdo de Paz en Colombia}

Como se ha señalado, el Acuerdo Final de Paz va a generar una nueva situación en el escenario internacional, en particular, con el restablecimiento de las relaciones internacionales entre los países involucrados en las acciones del narcotráfico de pasta básica de cocaína. Corresponde, aquí, destacar los siguientes aspectos:

a. Los países productores de hoja de coca también son productores de pasta básica de cocaína, pero no tienen injerencia directa o indirecta en su distribución en el ámbito internacional.

b. En Colombia, los carteles de coca habían logrado constituir al país como un referente de acopio y distribución para Estados Unidos, Europa y Asia. Ahora Colombia comparte esta condición con México.

c. En México, los carteles han constituido un referente de comercialización y distribución de pasta básica de cocaína en el mundo, gene- 
rando una condición particular y especial en una estructura de tercer nivel: las actividades societarias, financieras y económicas superan el contexto nacional y son internacionales. Conforme a esto, se ha generado una nueva plataforma de acción: el lavado de activos a nivel internacional (Stack, 2007).

d. Los Estados Unidos, frente a Europa, asumen una nueva política de confrontación contra grupos vinculados al narcotráfico, debido a la incidencia del efecto económico que se genera en su economía, y han relegado a un segundo plano el ámbito del impacto negativo en la salud pública a su población de adictos.

El contexto estratégico de la lucha contra el narcotráfico se registra en acciones especiales y directas como la creación del Plan Colombia (1999), la extradición de líderes de carteles a su jurisdicción penal y la vinculación económica agroexportadora de países como Perú, Colombia, Ecuador y Bolivia, según las condiciones de cada país (Klingner \& Moreno, 2014).

Un panorama sumamente complicado de evaluar, porque el narcotráfico representa dos aspectos de un mismo problema, pero, por condiciones de geopolítica, solo registra una acción: la lucha contra el narcotráfico, que provoca un contexto financiero de repercusión internacional. En efecto, el narcotráfico, como problema de salud pública, no reviste la misma importancia para los Estados Unidos, que también es afectado por otras formas de tráfico ilegal sobre las cuales no se ha generado ninguna acción formal o directa de parte del Gobierno federal. En cambio, las acciones vinculadas al lavado de activos sí registran una notoria importancia, especialmente porque a través de esta acción directa se puede controlar el beneficio económico que produce dicho flagelo en su propia jurisdicción.

\section{Una nueva geopolítica en la región}

Puesto que con la firma del Acuerdo Final de Paz en Colombia se producirá un nuevo contexto en el ámbito internacional, surge la necesaria evalua- 
ción de cuáles serán acciones a ejecutar por parte de los grupos vinculados a la comercialización de la pasta básica de cocaína en la región. Ante este contexto es se plantean algunas situaciones especiales:

a. Los gobiernos de Perú y Colombia, en forma particular, optarán por ampliar el nivel de intervención de sus Fuerzas Armadas y Fuerzas Militares en las regiones donde habitualmente se registraban cultivos de hoja de coca o en zonas de aterrizaje para el transporte de pasta básica de cocaína.

Esto provocará en forma directa el incremento de los precios de la pasta básica de cocaína en México y en los Estados Unidos, con lo cual la participación de grupos de narcotraficantes en ambos países provocarán nuevos escenarios de acción.

b. Tanto en Perú como en Colombia se generará una ampliación y mejoramiento de las vías de comunicación, lo cual provocará una mayor integración de los territorios tradicionalmente ocupados por grupos terroristas al ámbito nacional.

La productividad y la industrialización de zonas tradicionalmente desfavorecidas provocará una limitación en el cultivo de hojas de coca en el Perú, con lo cual se incrementará proporcionalmente esta actividad en Bolivia.

c. Las conexiones en tercer nivel del narcotráfico a nivel de lavado de activos provocará la identificación de los principales ejes de manejo de capitales provenientes de la coca y ello provocará el incremento de la corrupción en los gobiernos de Perú, Colombia y México, dado que esto resultará mucho más rentable que generar la misma acción en los Estados Unidos de América.

d. Se modificarán los mecanismos de traslado de pasta básica de cocaína y se provocarán nuevos acuerdos migratorios y de traslado de mercancías en las aduanas con los Estados Unidos de América, Europa y Asia en detrimento de las soberanías de Perú, Bolivia, Colombia y México, que serán condicionados con nuevos mecanismos reglamentarios que elevarán los costos de transporte de exportación e importación. 
Como se podrá observar, no resulta difícil ejecutar una proyección sobre la base de los registros históricos frente al problema del narcotráfico, el cual ha reformulado sus estrategias de operatividad, toda vez que se ha visto limitado por los gobiernos de los países involucrados en la cosecha, producción, transporte y distribución de pasta básica de cocaína.

\section{Conclusiones}

En el ámbito de las relaciones internacionales, surgen mecanismos de interacción entre diferentes países supeditados a diversos factores o condiciones. Factores políticos, económicos, comerciales o militares son, en esencia, los puntos de referencia a partir de los cuales se establecen las nuevas relaciones internacionales entre países cuya categoría no es equivalente en el contexto mundial.

Sobre esta realidad, es posible observar que las relaciones entre países está determinada por la ponderación de sus intereses nacionales, con dependencia de su realidad geopolítica y nacional. Esta situación particular da lugar a un nuevo contexto internacional para la región latinoamericana, en especial, aquellas zonas bajo el influjo de los efectos del Acuerdo Final de Paz en Colombia, cuyo narcotráfico ha perdido un aliado estratégico, factor que lo obligará a modificar sus acciones.

\section{Referencias}

Arce, L. (2007). Polay Campos: la capitulación en un libro. El Diario Internacional. http://www. eldiariointernacional.com/spip.php?article1388

Basombrío, C., \& Rospigliosi, F. (2006). La seguridad y sus instituciones en el Perú a inicios del siglo XXI. Reformas democráticas o neomilitarismo. IEP.

Contreras, C. (2014). Historia minima del Perú. El Colegio de México.

De La Pedraja, R. (2016). Free trade and social conflicto in Colombia, Perú and Venezuela: confronting U.S. capitalism, 2000-2016. McFarland \& Company Inc. Plublishers.

Del Alcàzar, J. (2007). Historia contemporánea de América. Universitat de València.

Jaskoski, M. (2013). Military politics and democracy in the Andes. Johns Hopkins University Press.

Klingner, D., \& Moreno, R. (2014). Using the "narcotrafico" threat to build public administration capacity between the US and Mexico. CRC Press. 
Marcy, W. (2010). The politics of cocaine: how U.S. foreign policy has created a thriving drug industry in Central and South America. Chicago Review Press.

Santana, A. (2004). El narcotráfico en América Latina. Siglo XXI Editores.

Stack, R. (2007). Los cárteles de México: pasado, presente y futuro. Crystal Entertainment.

Tokatlian, J. (2000). Globalización, narcotráfico y violencia: siete ensayos sobre Colombia. Grupo Editorial Norma.

Torres, A. (2009). El juego del camaleón: los secretos de Angostura. Eskeletra Editorial.

Villamarín, L. (2014). La selva roja. Ediciones LAVP. 